\title{
A Comprehensive Study of Microsatellite Instability Testing And Its Comparison With Immunohistochemistry In Gastric And Colorectal Cancers
}

\section{Yujun Park}

Department of Pathology, Seoul National University Bundang Hospital, Seoul National University College of Medicine

\section{Soo Kyung Nam}

Department of Pathology, Seoul National University Hospital, Seoul National University College of Medicine

\section{Soo Hyun Seo}

Department of Laboratory Medicine, Seoul National University Bundang Hospital, Seoul National University College of Medicine

\section{Kyoung Un Park}

Department of Laboratory Medicine, Seoul National University Bundang Hospital, Seoul National University College of Medicine

\section{Sang-Hoon Ahn}

Department of Surgery, Seoul National University Bundang Hospital, Seoul National University College of Medicine

\section{Heung-Kwon Oh}

Department of Surgery, Seoul National University Bundang Hospital, Seoul National University College of Medicine

\section{Duck-Woo Kim}

Department of Surgery, Seoul National University Bundang Hospital, Seoul National University College of Medicine

\section{Do Joong Park}

Department of Surgery, Seoul National University Hospital, Seoul National University College of Medicine

\section{Sung-Bum Kang}

Department of Surgery, Seoul National University Bundang Hospital, Seoul National University College of Medicine

\section{Hyung-Ho Kim}

Department of Surgery, Seoul National University Bundang Hospital, Seoul National University College of Medicine 


\section{Hye Seung Lee ( $\nabla$ hye2@snu.ac.kr)}

Department of Pathology, Seoul National University Hospital, Seoul National University College of Medicine

\section{Research Article}

Keywords: microsatellite instability, mismatch repair protein, immunohistochemistry, gastric cancer, colorectal cancer

Posted Date: September 7th, 2021

DOI: https://doi.org/10.21203/rs.3.rs-817395/v1

License: (c) (i) This work is licensed under a Creative Commons Attribution 4.0 International License. Read Full License 


\section{Abstract}

\section{Background}

Microsatellite instability (MSI) testing was comprehensively analyzed and compared with immunohistochemistry (IHC) for the mismatch repair (MMR) protein in gastric cancer (GC) and colorectal cancer (CRC).

\section{Methods}

PCR-based MSI testing was performed to compare the tumor and non-neoplastic normal tissues using five microsatellites consisting of two mononucleotide (BAT-26, BAT-25) and three dinucleotide (D5S346, D2S123, and D17S250) in 5,676 GC and 2,553 CRC cases. IHC for the MMR protein MLH1 was done in GCs, and IHC for four MMR proteins (MLH1, MSH2, MSH6, and PMS2) was performed in CRCs. Reviews were carried out for discordant or indeterminate IHC cases (such as focal loss of expression, equivocal expression, or abnormal expression patterns).

\section{Results}

MSI-high (MSI-H) and MMR-deficient (dMMR) expression was observed in 521 (9.2\%) GC and 171 (6.7\%) CRC cases. Discordance between MSI testing and IHC as well as indeterminate IHC cases accounted for $54(0.9 \%)$ and $29(1.1 \%)$ cases out of all GC and CRC cases, respectively, but accounted for $9.4 \%$ and $14.1 \%$ out of $575 \mathrm{GC}$ and $205 \mathrm{CRC}$ cases, respectively, excluding unequivocal microsatellite stable/MSIlow and MMR-proficient (pMMR) expression cases. pMMR expression was observed in most of the MSI-H GCs and CRCs consisting of only one unstable BAT-25 mononucleotide marker or solely of dinucleotide markers.

\section{Conclusions}

Considering the low incidence of MSI-H or dMMR expression, discordant or indeterminate $\mathrm{IHC}$ and/or MSI results were occasionally identified in GC and CRC cases, requiring complementary testing. These findings provide evidence for MSI testing and MMR IHC in routine clinical practice.

\section{Introduction}

Defective DNA mismatch repair (MMR) leads to alterations in the length of the repetitive sequence, a molecular phenomenon known as microsatellite instability (MSI) (1). The key to DNA MMR defects is the inactivation of MMR genes by hypermethylation and epigenetic silencing of $M L H 1$ in most sporadic tumors (2) or by germline mutation in one of the MMR genes in most Lynch syndrome cases (3). Approximately $15 \%$ of the colorectal cancers (CRCs) displayed MSI, most of which were sporadic tumors, but up to $3 \%$ of all the CRC cases were associated with Lynch syndrome (1). In gastric cancer (GC), MSI has been identified as one of the molecular subgroups (4) that is mostly caused by hypermethylation in the $M L H 1$ promoter (5). 
Some studies have shown that MSI-high (MSI-H) status can predict tumor prognosis and response to adjuvant therapy for patients with CRC or GC. For example, MSI-H CRC had an improved prognosis and oxaliplatin chemosensitivity but no observable benefit from fluorouracil-based adjuvant chemotherapy (1). In GC, a recent meta-analysis reported that MSI-H patients had a better prognosis than microsatellite stable (MSS) patients (6). However, MSI-H GC appears to be unchanged or even negatively impacted by adjuvant chemotherapy (7). This result was similarly observed across two recent phase III randomized controlled trials (8). In addition to prognostic capacities, MSI-H or MMR-deficient (dMMR) protein expression has been proven to serve as a biomarker that predicts the response to immune checkpoint inhibitors in advanced solid cancers (9). Pembrolizumab was approved by the U.S. Food and Drug Administration as a cancer type- or site-agnostic treatment for patients with advanced MSI-H or dMMR solid tumors (10).

dMMR protein expression is generally assessed by immunohistochemistry (IHC) for four MMR proteins (MLH1, MSH2, MSH6, and PMS2), and MSI status is examined by polymerase chain reaction (PCR)based MSI analysis. IHC is easily available, cost-effective, and directly identifies affected MMR genes. However, various staining patterns, such as weak staining, heterogeneous staining, and equivocal staining, were also observed and contributed to uncertain interpretations of IHC results $(11,12)$. One recent study has reported that most institutions accept IHC results alone for MMR proteins, and the discordant rate between IHC and PCR ranged from $1-10 \%$ in many cases (13). Some studies have reported low discordant rates between IHC and PCR in GC $(14,15)$, but there are no similar large-scale comparative studies that evaluate CRC. In this study, we compared IHC for MMR proteins and PCR-based analyses of MSI in our large-scale GC and CRC cohorts and evaluated the discordant rate as well as the frequency of uncertain IHC interpretation.

\section{Materials And Methods}

\section{Patients and samples}

In total, 5,676 patients with GC and 2,553 patients with CRC who underwent surgical resection at Seoul National University Bundang Hospital (Seongnam-si, Republic of Korea) between 2008 and 2018 were evaluated in this study. GC and CRC specimens resected through surgery were made from formalin-fixed, paraffin-embedded tissues. For all cases, tumor tissues and their corresponding non-neoplastic mucosa tissues were selected from the representative paraffın-embedded blocks.

\section{PCR-based MSI testing}

To evaluate MSI status, macrodissection and DNA extraction were performed in the tumor and nonneoplastic normal tissues of the same specimens. DNA extraction (InstaGene Matrix; Bio-Rad, Hercules, CA, USA) were subjected to PCR using the National Cancer Institute $(\mathrm{NCl})$ panel of five markers, including two mononucleotide (MT) markers (BAT-26 and BAT-25) and three dinucleotide (DT) markers (D5S346, D17S250, and D2S123). PCR products were analyzed with an automated sequencer (ABI 3731 Genetic Analyzer; Applied Biosystems, Foster City, CA, USA). Microsatellite status was assessed to determine 
changes in the allele profiles of tumor cells compared to the corresponding non-neoplastic normal tissues. MSI-H was defined as two or more $\mathrm{NCl}$ markers with unstable peaks, and MSI-low (MSI-L)/MSS was defined as one or no $\mathrm{NCl}$ marker with unstable peaks (16). Repeated examination was performed if PCR failed or the results were indeterminate.

\section{MMR protein expression for IHC}

Immunohistochemical stains for MLH1, MSH2, MSH6, and PMS2 were performed on each specimen according to the manufacturer's instructions: MLH1 (mouse monoclonal primary antibody, prediluted, clone M1; Ventana, Tucson, AZ, USA), MSH2 (mouse monoclonal primary antibody, 1:200, clone G2191129; Cell Marque, Rocklin, CA, USA), MSH6 (mouse monoclonal primary antibody, 1:100, clone 44; Cell Marque), and PMS2 (mouse monoclonal primary antibody, prediluted, clone ERP3947; Ventana) were stained using the Benchmark XT staining and ULTRA systems (Ventana).

\section{Interpretation of IHC for MMR protein expression}

MMR protein expression was assessed by determining the nuclear staining of tumor cells compared to internal positive control tissues, such as non-neoplastic epithelial cells, stromal cells, and lymphocytes, in the vicinity of the tumor. Each case was classified into one of four categories according to the intensity and proportion of tumor nuclear staining in the whole slide as follows: (1) "intact expression" was defined as unequivocal nuclear staining in all tumor cells with clear staining of internal control tissue adjacent to the tumor cells (Fig. 1A), (2) "loss of expression" was defined as unequivocal loss of nuclear staining in all tumor cells with clear staining of internal control tissue in the vicinity of the tumor (Fig. 1B), (3) "focal loss of expression" was defined as clearly demarcated regional loss of tumor nuclear staining with internal control tissue adjacent to the tumor cells showing clear staining (Fig. 1C), and (4) "equivocal expression" was defined as a case where both the tumor and internal control tissue stains were very faint or unstained (Fig. 1D) $(17,18)$. MMR-proficient (pMMR) expression was defined as intact expression of all four MMR proteins, and dMMR expression was defined as the loss of both MLH1 and PMS2, both MSH2 and MSH6, or the isolated loss of MSH6 or PMS2 (12). Focal loss of expression or equivocal expression cases were classified as indeterminate IHC cases. Additionally, cases showing abnormal MMR protein expression patterns (Fig. 1E-1H) were classified as indeterminate IHC staining.

\section{Comparison between IHC for MMR protein expression and MSI analysis by PCR}

All cases with GC or CRC were tested for PCR-based MSI. IHC for MLH1 expression was performed in all GCs because most MSI-H GCs were associated with hypermethylation of MLH1 (5), and IHC for the four MMR proteins was performed in all CRCs. In cases showing discordance between the IHC and MSI statuses or indeterminate $\mathrm{IHC}$ or MSI testing results, both MSI testing and IHC of MMR proteins were reevaluated. Briefly, the original immunohistochemically-stained slide was reviewed, and both IHC and PCR were performed for the tested blocks. If necessary, the same tests were performed for additional blocks of the same specimen. Discordant or indeterminate IHC results for GC cases were further analyzed by $\mathrm{IHC}$ for MSH2, MSH6, and PMS2. 


\section{Statistical analysis}

All analyses and graphs were conducted using R.4.0.1, R-studio 1.2.5033, and GraphPad Prism 8 (GraphPad Software, Inc., San Diego, CA, USA).

\section{Results}

\section{Initial comparative evaluation between MSI and IHC tests}

A comparative analysis between IHC for MMR protein expression and PCR-based MSI testing was performed in 5,676 GC and 2,553 CRC cases.

In the GC cases, 5,082 cases (89.5\%) showed MSS/MSI-L and pMMR expression, 503 cases (8.9\%) showed MSI-H and dMMR expression. As a result of the initial comparison between MSI testing and IHC, re-evaluation of MSI testing and $\mathrm{IHC}$ was necessary in 91 discordant or indeterminate $\mathrm{IHC}$ cases $(15.3 \%)$ among the 594 cases showing MSI-H and loss of MLH1 (Fig. 2A). After re-evaluation, 37 cases of agreement between MSI testing and IHC for MMR proteins were confirmed. Among them, 17 cases resulted from misinterpretation (Fig. 3A and 3B), and 12 cases were impacted by problems in the immunohistochemical process (Fig. 3C and 3D). The remaining eight cases displayed loss of expression in other MMR proteins (MSH2, MSH6, and PMS2), six of which involved loss of MSH2/MSH6 expression.

In the CRC cases, 2,343 cases (91.8\%) showed MSS/MSI-L and pMMR expression, and 171 cases (6.7\%) showed MSI-H and dMMR expression. As a result of the initial comparison between MSI testing and IHC, re-evaluation of MSI testing and $\mathrm{IHC}$ was necessary in 39 discordant or indeterminate $\mathrm{IHC}$ cases $(18.6 \%)$ among the 210 cases showing MSI-H and dMMR expression (Fig. 2B). After re-evaluation, 10 cases of agreement between MSI testing and IHC for MMR were confirmed. Similar to the GC cases, the discordant cases and indeterminate $\mathrm{IHC}$ results stemmed from six cases of misinterpretation and four cases with problems during immunohistochemical staining.

\section{MSI testing and IHC for MMR protein expression after reevaluation}

The MSS, MSI-L, and MSI-H statuses of all GC cases were 4,803 (84.6\%), 314 (5.5\%), and 559 (9.8\%), respectively, and those of all CRC cases were 2,149 (84.2\%), 208 (8.1\%), and 196 (7.7\%), respectively (Fig. 4A and 4C). In MSI-L cases, a DT marker in the NCI panel was unstable in most GCs (92.4\%) and CRCs (96.2\%) (Fig. 5A and 5C). Additionally, the diagnostic sensitivity of MSI-H was higher with the MT markers than that with DT markers (Fig. 5B and 5D).

Among the total of 5,676 GC cases, dMMR protein expression was found in 524 cases (9.2\%), and indeterminate IHC was observed in 35 cases (0.6\%) (Fig. 4B). In addition, 5,101 cases (89.9\%) showed MSS/ MSI-L and pMMR protein expression, and 521 cases (9.2\%) showed MSI-H and, dMMR protein expression (Fig. 6A). After re-evaluation, discordant or indeterminate IHC cases were found in 54 out of 5,676 cases $(0.9 \%)$ and 575 cases (9.4\%), excluding unequivocal MSS/MSI-L and pMMR expression cases (Fig. 6C). 
Among the total of 2,553 CRC cases, dMMR protein expression was found in 177 cases (6.9\%), and indeterminate IHC was observed in 21 cases (0.8\%) (Fig. 4D). In addition, 2,348 cases (92.0\%) showed MSS/ MSI-L and pMMR protein expression, and 176 cases (6.9\%) showed MSI-H and, dMMR protein expression (Fig. 6B). After re-evaluation, discordant or indeterminate results were found in 29 out of 2,553 cases (1.1\%), and 205 cases (14.1\%), excluding unequivocal MSS/MSI-L and pMMR expression cases (Fig. 6D).

\section{Discordant and indeterminate IHC cases}

In regard to the nineteen discordant GC cases, sixteen cases displayed MSI-H/pMMR protein expression. Seven of the MSI-H/pMMR expression cases were composed of only unstable DT markers, with no unstable MT markers (36.8\%), six cases contained only one unstable MT marker (31.6\%), and the remaining three cases were MSI-H GCs with two unstable MT markers (15.8\%) (Fig. 7A). As for the eight discordant CRC cases, seven cases displayed MSI-H/pMMR protein expression, five of which were MSI-H composed of no unstable MT markers and only unstable DT markers (62.5\%), one of which contained only one unstable MT marker (12.5\%), and the remaining one was a MSI-H CRC with two unstable MT markers (12.5\%) (Fig. 7B).

In cases of GC and CRC-except for indeterminate IHC-when there were only one or no unstable MT markers, MSI-H/pMMR expression cases comprised 13 out of $20 \mathrm{GC}$ cases $(65.0 \%)$ and six out of $11 \mathrm{CRC}$ cases (54.5\%), respectively (Fig. 7C and 7D). MSI-H and pMMR GC and CRC cases with only unstable DT markers were found in seven out of eight GC cases (87.5\%) and five out of six CRC cases (83.3\%)-except for indeterminate IHC. The BAT-25 MT marker was always unstable in MSI-H/pMMR GC and CRC cases with only one unstable MT marker. In the NCl panel of five markers, the D2S123 DT marker showed the most unstable cases (91.3\%) in MSI-H/pMMR GC and CRC cases (Fig. 7E).

In the GC cases with indeterminate IHC results, $14 \mathrm{MSI}-\mathrm{H}$ and $10 \mathrm{MSS} / \mathrm{MSI}-\mathrm{L}$ cases showed focal loss. All focal loss IHC results in GC cases were observed in MLH1 or PMS2 (Fig. 8A). In the indeterminate IHC CRC cases, five MSI-H cases and two MSS/MSI-L cases showed focal loss, and all focal loss IHC results observed in MSI-H cases involved MSH6 (Fig. 8B). Abnormal MMR IHC patterns were observed in only two MSI-H CRC cases, one of which lost all MMR protein expression.

\section{Discussion}

MSI is a molecular phenotype observed across a variety of sporadic cancers(19) but is particularly important in CRC for the following reasons: identification of Lynch syndrome, prognosis, and response to chemotherapy (12). In GC, MSI status has been classified into molecular subgroups that are included in both The Cancer Genome Atlas (4) and the Asian Cancer Research Group (20) studies with increasing importance for the same reasons as in CRC. Furthermore, in all advanced solid cancers, both tests have become even more important as tumors with either MSI-H or dMMR are candidates for immunotherapy (12). The purpose of this study was to evaluate the reliability and accuracy of IHC staining for MMR 
deficiency compared to PCR-based MSI testing with clinical significance in large-scale GC and CRC cohorts.

In previous studies, MSI-H or dMMR GCs and CRCs have been reported at various rates (12). The overall proportion of MSI-H or dMMR GCs and CRCs varies depending on the patient cohorts, markers used for PCR-based MSI testing, types of tissues used in IHC analysis, and types of antibodies. In this study, PCRbased MSI tests were performed on both normal and tumor tissues, and IHC for MMR protein expression was performed on whole tissue blocks, not tissue microarrays. Thus, MSI-H or dMMR protein expression was observed in $9.9 \%$ of the GCs and $7.7 \%$ of the CRCs.

Our study showed a remarkably low discordant rate of $<1 \%$ between IHC for MMR protein expression and PCR-based MSI testing in both GC and CRC. The discordant rate between these assays previously reported for CRC ranged from $1-10 \%(21,22)$, but a recent study showed a discordant rate of $<1 \%$, similar to that observed in our study (13). The discordant rate in GC was lower than the published rate of $4 \%-9 \%(14,15)$. This discrepancy between MSI testing and IHC for MMR proteins-as in our study-is likely the result of various causes, such as misinterpretation and IHC staining issues (18). However, even after re-evaluation, some discordant cases were observed in both GC and CRC cases. Previous studies have reported that rare missense mutations affecting protein functions other than protein translation and antigenicity are mainly observed in MLH1 and MSH6 genes with pMMR expression observed in IHC (23, 24). Additional tests, such as next-generation sequencing, are needed to confirm the aforementioned missense mutations. Additionally, further examination of the clinical outcomes of discordant cases such as MSS/MSI-L and dMMR expression as well as MSI-H/pMMR expression is required.

The present study showed that $<1 \%$ of the cases displayed unusual staining patterns for MMR protein expression, such as focal loss of expression and equivocal expression, in both GCs and CRCs. The apparent incidence of uncertain staining patterns remains unclear, but $<10 \%$ of such cases have been reported in CRCs and endometrial cancers $(17,25)$. Twenty-four cases of uncertain pattern staining in our GC cases displayed focal loss of MHL1 protein expression, and recent study showed that regions with subclonal loss of MLH1 and PMS2 protein expression were commonly associated with MLH1 hypermethylation, suggesting intratumoral heterogeneity in sporadic tumors (17). Similar to our findings, previous studies have observed MSI-H CRC in most cases of focal loss of MSH6 protein expression, which showed somatic instability in the $\mathrm{C} 8$ repeat region of $\mathrm{MSH} 6$ gene and suggested a secondary event during tumor progression (26). Abnormal staining patterns, such as the loss of all four MMR proteins, have rarely been reported thus far, and the molecular mechanism remains unknown $(21,22)$. All of our cases with this staining pattern were MSI-H, but further studies are needed to fully elucidate the clinical significance.

Importantly, the proportion of disagreement between IHC and PCR as well as indeterminate staining patterns for IHC comprised approximately $10 \%$ of the GC and CRC cases, excluding unequivocal MSS/MSI-L and pMMR expression cases. In the case of indefinite IHC results, repeat testing is recommended (11). However, suboptimal fixation was also a major cause of unusual staining patterns, 
such as equivocal expression, in which case it might be difficult to correctly interpret the results even after repeated tests (27). Accurate determination is critical because, as stated previously, MSI-H or dMMR GC and CRC cases are candidates for immunotherapy. In addition, indeterminate IHC cases should be clearly identified because they are also potential candidates for immunotherapy. Thus, as the importance of identifying MSI-H and dMMR expression increases, recent research recommends performing PCR-based MSI tests on cases with indeterminate IHC staining $(12,13,18)$. Recent studies have also shown that misdiagnosed MMR protein expression and MSI status are the primary negative factors for response to immune checkpoint inhibitors and recommend that both IHC and PCR tests should be performed for candidates for treatment with immune checkpoints inhibitors and evaluated for discordant results between IHC and PCR (28). In our study, the proportion of discordant cases among the total MMR IHC results decreased while that of the indeterminate $\mathrm{IHC}$ results did not decrease. The discordant cases were not completely resolved; therefore, PCR-based MSI tests and MMR IHC tests should be executed in a complementary manner for more accurate determination.

In a previous study comparing the detection of MMR deficiency using an $\mathrm{NCl}$ panel of two MT and three DT markers versus a panel of only five MT markers (BAT-26, BAT-25, NR-21, NR-22, and NR-24), the latter panel was more sensitive and had a higher positive predictive value. Additionally, IHC for MMR protein expression in all MSI-H CRC cases consisted of unstable DT markers and one or no unstable MT markers among the $\mathrm{NCl}$ panel confirming all normal MMR protein expression (29). The $\mathrm{NCl}$ follow-up workshop also recommended for MSI-H cases consisting only of mutated DT markers and can be examined with a secondary panel consisting of MT markers (16). In our study, normal MMR proficiency was also observed in most of the MSI-H GCs and CRCs consisting of only one unstable BAT-25 MT marker or solely of DT markers. Therefore, special care must be taken when interpreting the results from MSI analyses if only the BAT-25 MT markers are unstable among the MT marker or only the DT markers are unstable.

This study has some limitations. First, only surgical specimens were compared with IHC for MMR protein expression and PCR-based MSI testing. In clinical practice, both tests are performed on biopsies; therefore, a comparative test between the two assays in biopsy specimens of GCs and CRCs is necessary. Second, a uniform process for interpretation of the prognostic significance and molecular basis of discordant cases and indeterminate staining results should be developed. Nonetheless, this study was a comparative study of large-scale GC and CRC cohorts, and PCR-based MSI tests were performed to compare the tumor and normal tissues in all cases to ensure the reliability of the results as much as possible.

In conclusion, the overall results showed a very low discordant rate between PCR-based MSI testing and MMR IHC methods in both the GC and CRC cohorts. However, the discordant or indeterminate rate was higher in GC and CRC cases, excluding unequivocal MSS/MSI-L and pMMR expression cases, because the MSI-H, dMMR, and indeterminate IHC results incidence was < $15 \%$ in both the GC and CRC cohorts. Complementary PCR-based MSI tests are required for cases that are difficult to identify with MMR IHC for more accurate and reliable diagnoses since discrepancies or uncertain IHC interpretations have 
occasionally been identified in GCs and CRCs. Thus, these findings provide evidence for MSI testing and MMR IHC in daily practice.

\section{Abbreviations}

MSI Microsatellite instability

IHC Immunohistochemistry

GC Gastric cancer

CRC Colorectal cancer

MMR mismatch repair

MSI-H MSI-high

dMMR MMR-deficient

pMMR MMR-proficient

MSS Microsatellite stable

MT Mononucleotide

DT Dinucleotide

MSI-L MSI-Iow

\section{Declarations}

\section{Ethics approval and consent to participate}

All human tissue samples were obtained from the archive of the Department of Pathology, Seoul National University Bundang Hospital. This study was conducted with the written consent of the all study participants and was approved by the institutional review board (IRB) of Seoul National University Bundang Hospital (IRB number: B-1905/538-307) and performed in accordance with the Declaration of Helsinki for biomedical research involving human subjects.

\section{Consent for publication}

Not applicable.

\section{Availability of data and materials}


The datasets used and/or analysed during the current study are available from the corresponding author on reasonable request.

\section{Competing interests.}

The authors declare that they have no competing interests.

\section{Funding}

This work was supported by the Technology development Program (S2638360) funded by the Ministry of SMEs and Startups (MSS, Korea). For the remaining authors none were declared.

\section{Authors' contributions}

Y.P. evaluated the IHC and MSI data, analyzed the overall data, and wrote this article. S.K.N. helped with the data collection. S.H.S. and K.U.P. performed the PCR-based MSI analysis. S.H.A., H.K.O., D.W.K., D.J.P., S.B.K., and H.H.K. provided the tissue samples and clinical information. H.S.L. collected all IHC and MSI data as well as designed this study. All authors read and approved the final manuscript.

\section{Acknowledgements}

Not applicable.

\section{References}

1. Vilar E, Gruber SB. Microsatellite instability in colorectal cancer-the stable evidence. Nat Rev Clin Oncol. 2010;7(3):153-62.

2. Muzny DM, Bainbridge MN, Chang K, Dinh HH, Drummond JA, Fowler G, et al. Comprehensive molecular characterization of human colon and rectal cancer. Nature. 2012;487(7407):330-7.

3. Latham A, Srinivasan P, Kemel Y, Shia J, Bandlamudi C, Mandelker D, et al. Microsatellite Instability Is Associated With the Presence of Lynch Syndrome Pan-Cancer. J Clin Oncol. 2019;37(4):286-95.

4. Bass AJ, Thorsson V, Shmulevich I, Reynolds SM, Miller M, Bernard B, et al. Comprehensive molecular characterization of gastric adenocarcinoma. Nature. 2014;513(7517):202-9.

5. Leung SY, Yuen ST, Chung LP, Chu KM, Chan AS, Ho JC. hMLH1 promoter methylation and lack of hMLH1 expression in sporadic gastric carcinomas with high-frequency microsatellite instability. Cancer Res. 1999;59(1):159-64.

6. Polom K, Marano L, Marrelli D, De Luca R, Roviello G, Savelli V, et al. Meta-analysis of microsatellite instability in relation to clinicopathological characteristics and overall survival in gastric cancer. $\mathrm{Br} J$ Surg. 2018;105(3):159-67.

7. Kim SY, Choi YY, An JY, Shin HB, Jo A, Choi H, et al. The benefit of microsatellite instability is attenuated by chemotherapy in stage II and stage III gastric cancer: Results from a large cohort with subgroup analyses. Int J Cancer. 2015;137(4):819-25. 
8. Choi YY, Kim H, Shin SJ, Kim HY, Lee J, Yang HK, et al. Microsatellite Instability and Programmed Cell Death-Ligand 1 Expression in Stage II/III Gastric Cancer: Post Hoc Analysis of the CLASSIC Randomized Controlled study. Ann Surg. 2019;270(2):309-16.

9. Le DT, Durham JN, Smith KN, Wang H, Bartlett BR, Aulakh LK, et al. Mismatch repair deficiency predicts response of solid tumors to PD-1 blockade. Science. 2017;357(6349):409-13.

10. Hargadon KM, Johnson CE, Williams CJ. Immune checkpoint blockade therapy for cancer: An overview of FDA-approved immune checkpoint inhibitors. Int Immunopharmacol. 2018;62:29-39.

11. Shia J. Immunohistochemistry versus microsatellite instability testing for screening colorectal cancer patients at risk for hereditary nonpolyposis colorectal cancer syndrome. Part I. The utility of immunohistochemistry. J Mol Diagn. 2008;10(4):293-300.

12. Luchini C, Bibeau F, Ligtenberg MJL, Singh N, Nottegar A, Bosse T, et al. ESMO recommendations on microsatellite instability testing for immunotherapy in cancer, and its relationship with PD-1/PD-L1 expression and tumour mutational burden: a systematic review-based approach. Ann Oncol. 2019;30(8):1232-43.

13. Hissong E, Crowe EP, Yantiss RK, Chen YT. Assessing colorectal cancer mismatch repair status in the modern era: a survey of current practices and re-evaluation of the role of microsatellite instability testing. Mod Pathol. 2018;31(11):1756-66.

14. Lee HS, Choi SI, Lee HK, Kim HS, Yang HK, Kang GH, et al. Distinct clinical features and outcomes of gastric cancers with microsatellite instability. Mod Pathol. 2002;15(6):632-40.

15. Bae YS, Kim H, Noh SH, Kim H. Usefulness of Immunohistochemistry for Microsatellite Instability Screening in Gastric Cancer. Gut Liver. 2015;9(5):629-35.

16. Umar A, Boland CR, Terdiman JP, Syngal S, de la Chapelle A, Ruschoff J, et al. Revised Bethesda Guidelines for hereditary nonpolyposis colorectal cancer (Lynch syndrome) and microsatellite instability. Journal of the National Cancer Institute. 2004;96(4):261-8.

17. Watkins JC, Nucci MR, Ritterhouse LL, Howitt BE, Sholl LM. Unusual Mismatch Repair Immunohistochemical Patterns in Endometrial Carcinoma. Am J Surg Pathol. 2016;40(7):909-16.

18. Sari A, Pollett A, Eiriksson LR, Lumsden-Johanson B, Van de Laar E, Kazerouni H, et al. Interobserver Agreement for Mismatch Repair Protein Immunohistochemistry in Endometrial and Nonserous, Nonmucinous Ovarian Carcinomas. Am J Surg Pathol. 2019;43(5):591-600.

19. Hause RJ, Pritchard CC, Shendure J, Salipante SJ. Classification and characterization of microsatellite instability across 18 cancer types. Nat Med. 2016;22(11):1342-50.

20. Cristescu R, Lee J, Nebozhyn M, Kim KM, Ting JC, Wong SS, et al. Molecular analysis of gastric cancer identifies subtypes associated with distinct clinical outcomes. Nat Med. 2015;21(5):449-56.

21. Hampel H, Frankel WL, Martin E, Arnold M, Khanduja K, Kuebler P, et al. Feasibility of screening for Lynch syndrome among patients with colorectal cancer. J Clin Oncol. 2008;26(35):5783-8.

22. Yuan L, Chi Y, Chen W, Chen X, Wei P, Sheng W, et al. Immunohistochemistry and microsatellite instability analysis in molecular subtyping of colorectal carcinoma based on mismatch repair competency. Int J Clin Exp Med. 2015;8(11):20988-1000. 
23. Klarskov L, Holck S, Bernstein I, Okkels H, Rambech E, Baldetorp B, et al. Challenges in the identification of MSH6-associated colorectal cancer: rectal location, less typical histology, and a subset with retained mismatch repair function. Am J Surg Pathol. 2011;35(9):1391-9.

24. Pino MS, Chung DC. Microsatellite instability in the management of colorectal cancer. Expert Rev Gastroenterol Hepatol. 2011;5(3):385-99.

25. Chapusot C, Martin L, Puig PL, Ponnelle T, Cheynel N, Bouvier AM, et al. What is the best way to assess microsatellite instability status in colorectal cancer? Study on a population base of 462 colorectal cancers. The American journal of surgical pathology. 2004;28(12):1553-9.

26. Graham RP, Kerr SE, Butz ML, Thibodeau SN, Halling KC, Smyrk TC, et al. Heterogenous MSH6 loss is a result of microsatellite instability within $\mathrm{MSH} 6$ and occurs in sporadic and hereditary colorectal and endometrial carcinomas. The American journal of surgical pathology. 2015;39(10):1370-6.

27. Klarskov L, Ladelund S, Holck S, Roenlund K, Lindebjerg J, Elebro J, et al. Interobserver variability in the evaluation of mismatch repair protein immunostaining. Hum Pathol. 2010;41(10):1387-96.

28. Cohen R, Hain E, Buhard O, Guilloux A, Bardier A, Kaci R, et al. Association of Primary Resistance to Immune Checkpoint Inhibitors in Metastatic Colorectal Cancer With Misdiagnosis of Microsatellite Instability or Mismatch Repair Deficiency Status. JAMA Oncol. 2019;5(4):551-5.

29. Xicola RM, Llor X, Pons E, Castells A, Alenda C, Pinol V, et al. Performance of different microsatellite marker panels for detection of mismatch repair-deficient colorectal tumors. Journal of the National Cancer Institute. 2007;99(3):244-52.

\section{Figures}




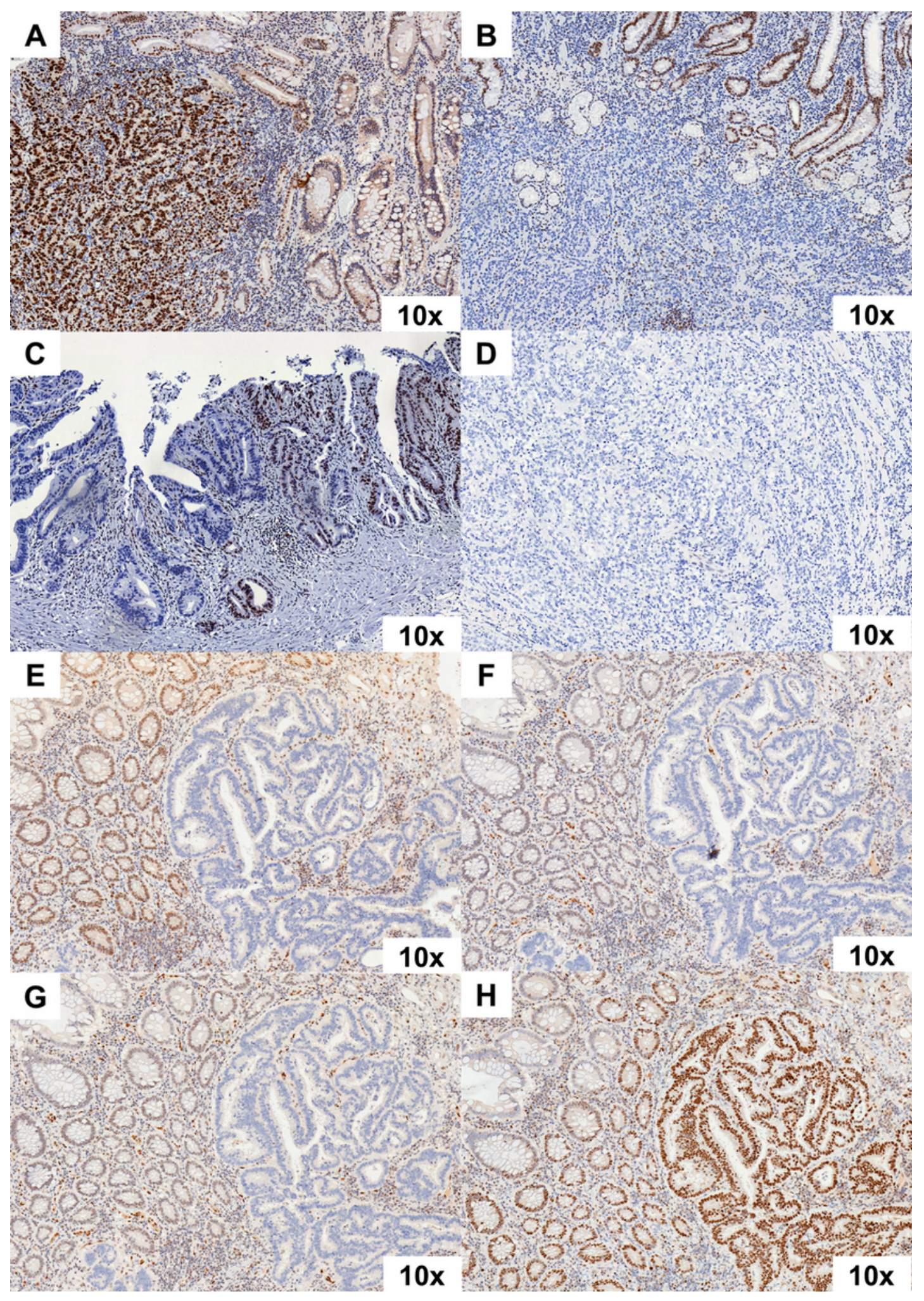

\section{Figure 1}

Representative IHC images of MMR protein expression. MSS case with intact MLH1 protein expression (A). MSI-H case with complete loss of MLH1 protein expression (B). MSI-H case with focal loss of MLH1 protein expression (C). MSI-H case with equivocal MLH1 protein expression (D). MSI-H case with abnormal patterns of MMR protein expression with complete loss of MLH1 (E), hMLH2 (F), and PMS2 (H) but intact MSH6 protein expression (G). All images are 100 magnification. 
A

GCs except MSS/MSI-L and MLH1 intact ( $\mathrm{N}=594)$

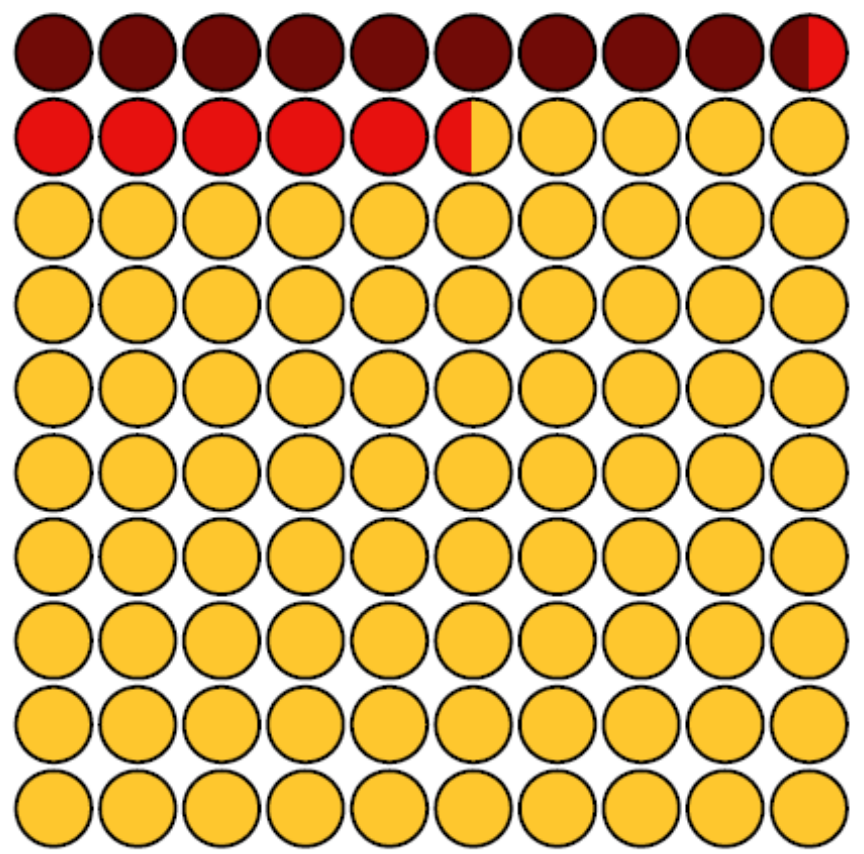

Discordant case $(\mathrm{N}=56,9.4 \%)$

口 Indeterminate IHC ( $\mathrm{N}=35,5.9 \%)$

$\square \mathrm{MSI}-\mathrm{H}$ and MLH1 loss ( $\mathrm{N}=503,84.7 \%$ )
B

CRCs except MSS/MSI-L and pMMR ( $\mathrm{N}=210)$

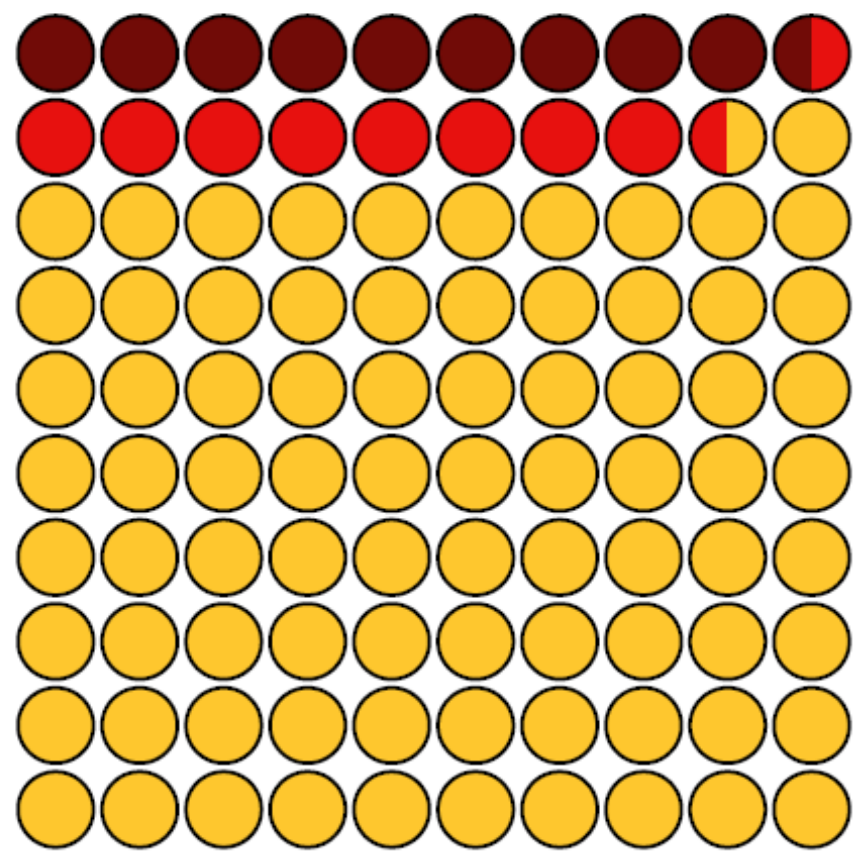

Discordant case ( $\mathrm{N}=20,9.5 \%$ )

Indeterminate IHC ( $\mathrm{N}=19,9.1 \%)$

MSI-H and dMMR ( $\mathrm{N}=171,81.4 \%)$

Figure 2

Initial discordant or indeterminate results observed in GCs (A) and CRCs (B), excluding MSS/MSI-L and pMMR cases. 


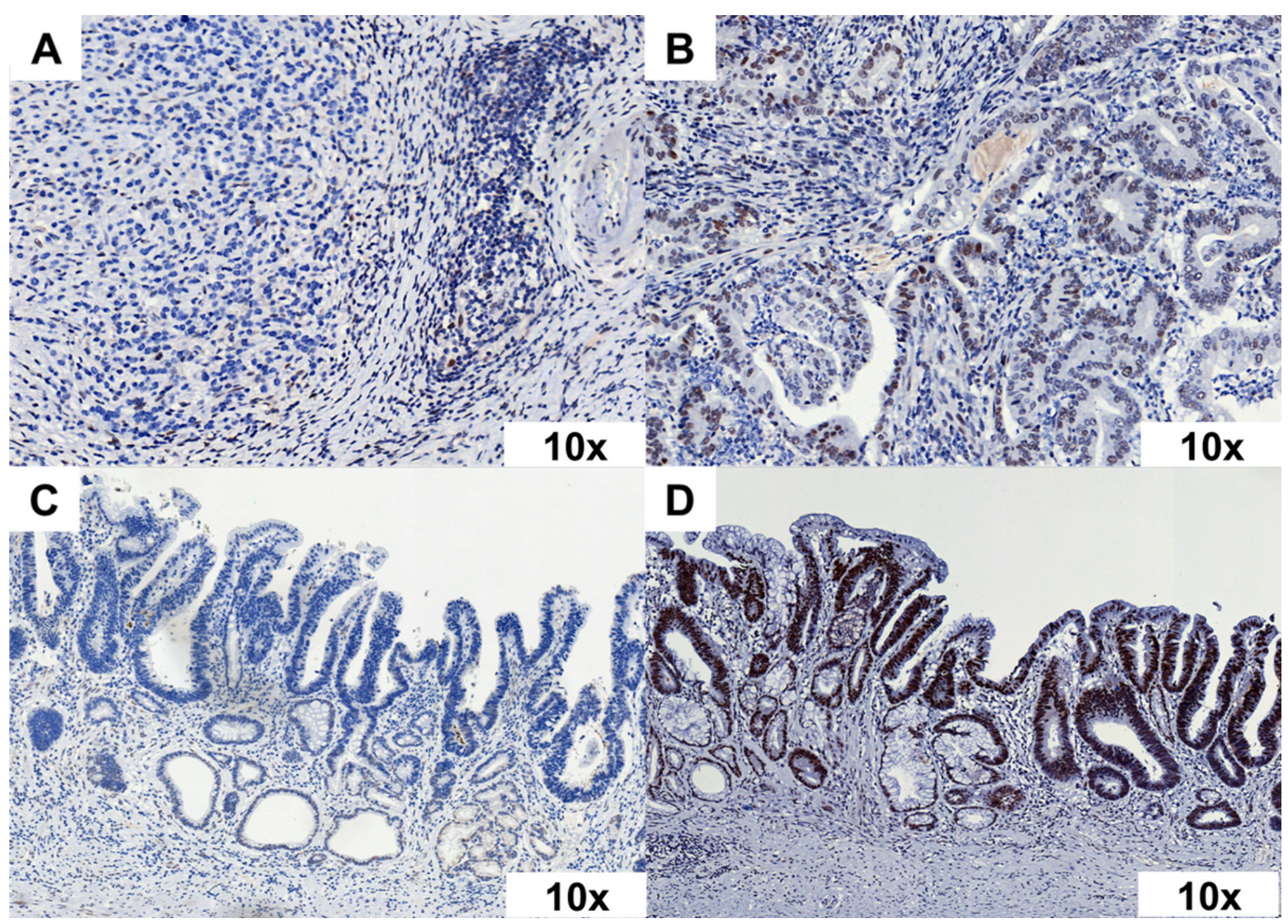

\section{Figure 3}

Representative IHC images from re-evaluated cases. At first, the MLH1 protein expression of this MSI-H case was classified as equivocal because the tumor cells and adjacent stromal cells were not stained. However, it was subsequently confirmed that the adjacent stromal cells were weakly stained, and the final determination showed complete loss (A). This MSS case with abnormal MLH1 protein expression patterns, including mixed variable loss and strong staining in tumor cells, was initially classified as equivocal. However, it was corrected to intact MLH1 protein expression because there was no evident area of regional loss (B). At first, this MSS case with equivocal MLH1 protein expression displayed that both the tumor cells and adjacent stromal cells were not stained (C). However, MLH1 protein IHC was performed on other paraffin-embedded blocks of the same tumor, and intact MLH1 protein expression was confirmed (D). All images are 100 magnification. 
PCR based MSI in GCs ( $\mathrm{N}=5,676)$

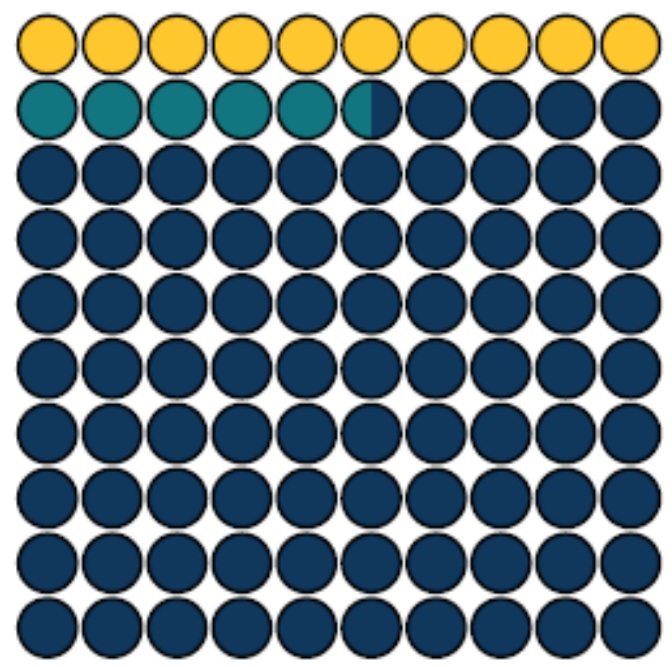

口 MSI-H (N = 559, 9.8\%)

D MSI-L ( $\mathrm{N}=314,5.5 \%)$

口MSS $(\mathrm{N}=4,803,84.6 \%)$

C

PCR based MSI in CRCs ( $\mathrm{N}=2,553)$

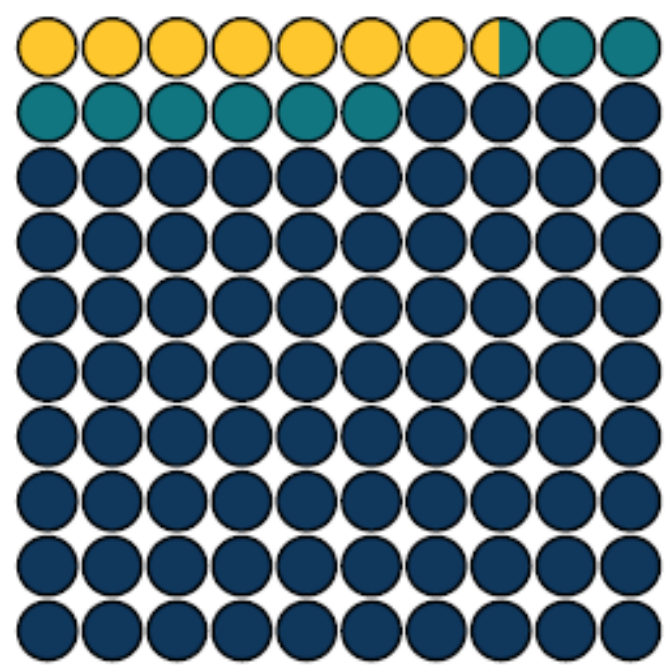

口 MSI-H (N = 196, 7.7\%)

口 MSI-L $(\mathrm{N}=208,8.1 \%)$

口MSS $(\mathrm{N}=2,149,84.2 \%)$
MMR IHC in GCs $(\mathrm{N}=5,676)$

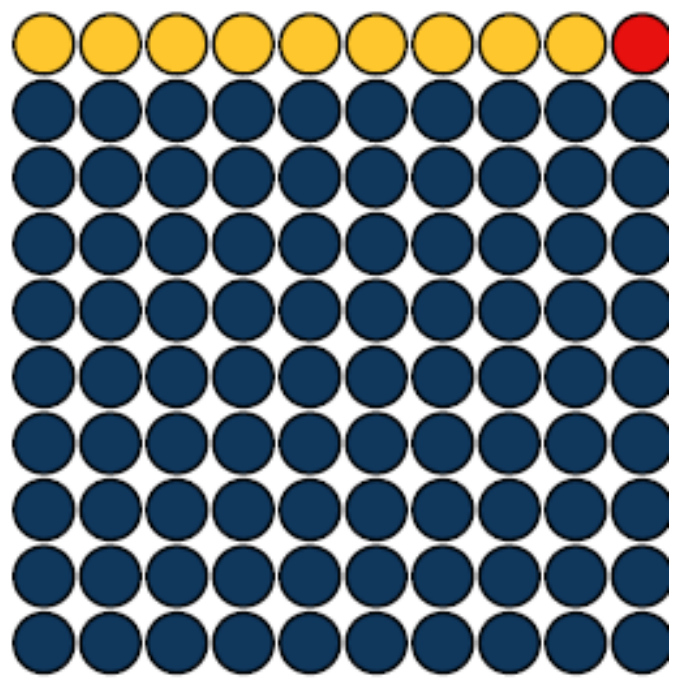

D dMMR ( $\mathrm{N}=524,9.2 \%)$

口 Indeterminate IHC ( $\mathrm{N}=35,0.6 \%)$

口MMR ( $\mathrm{N}=5,117,90.2 \%)$

D

MMR IHC in CRCs $(\mathrm{N}=2,553)$

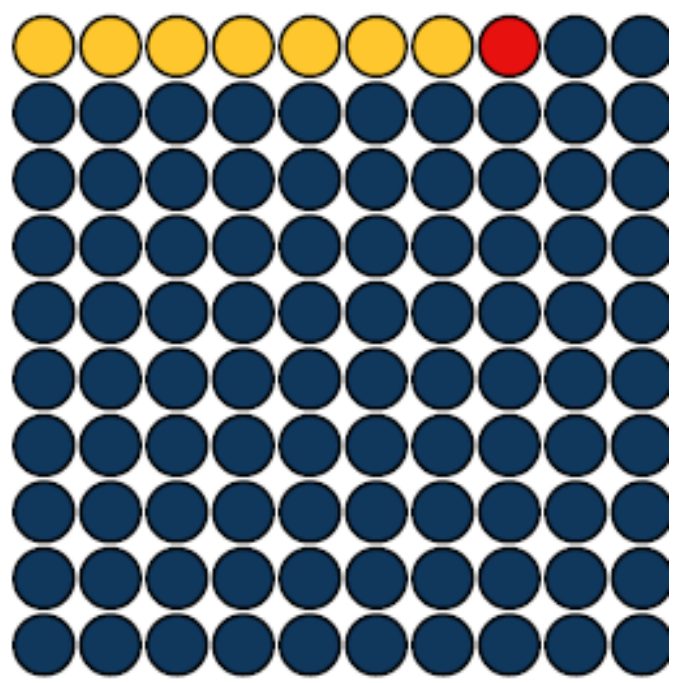

$\square$ dMMR ( $N=177,6.9 \%$ )

$\square$ Indeterminate $\mathrm{IHC}(\mathrm{N}=\mathbf{2 1}, \mathbf{0 . 8 \%})$

DMMR ( $\mathrm{N}=2,355,92.3 \%)$

Figure 4

PCR-based MSI and MMR protein IHC in GCs and CRCs. MSI testing (A) and MMR protein IHC (B) in GCs. MSI testing (C) and MMR protein IHC (D) in CRCs. 
a

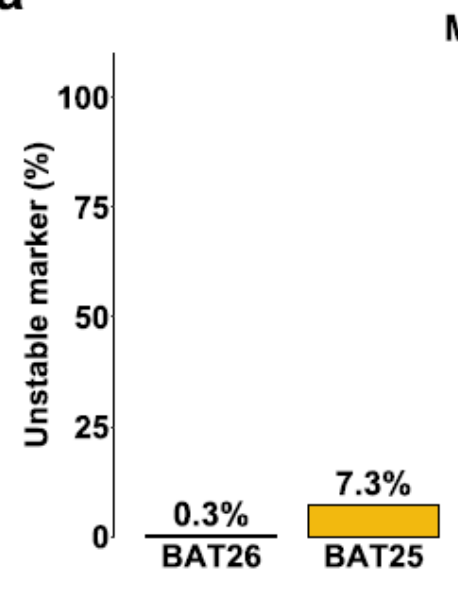

MSI-L GCs

C

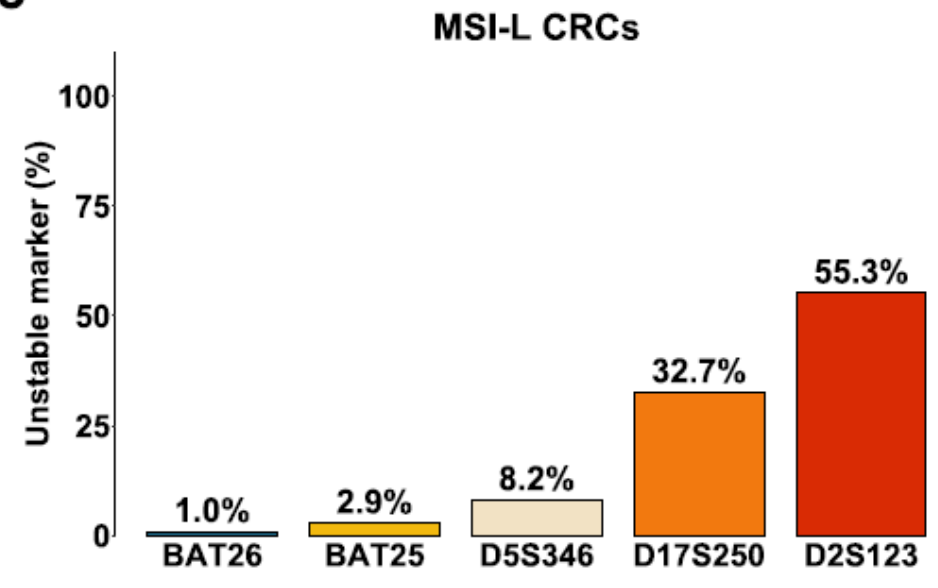

b

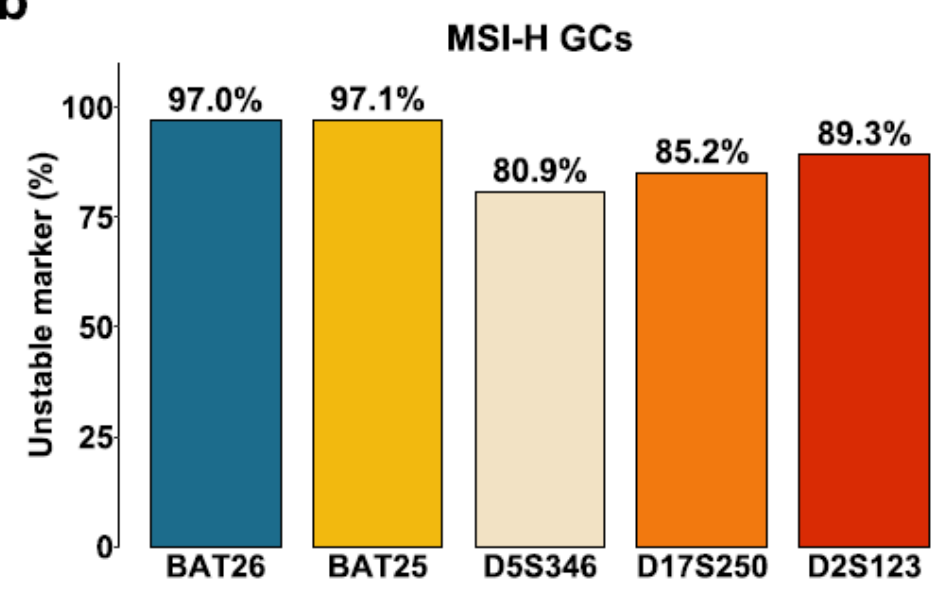

d

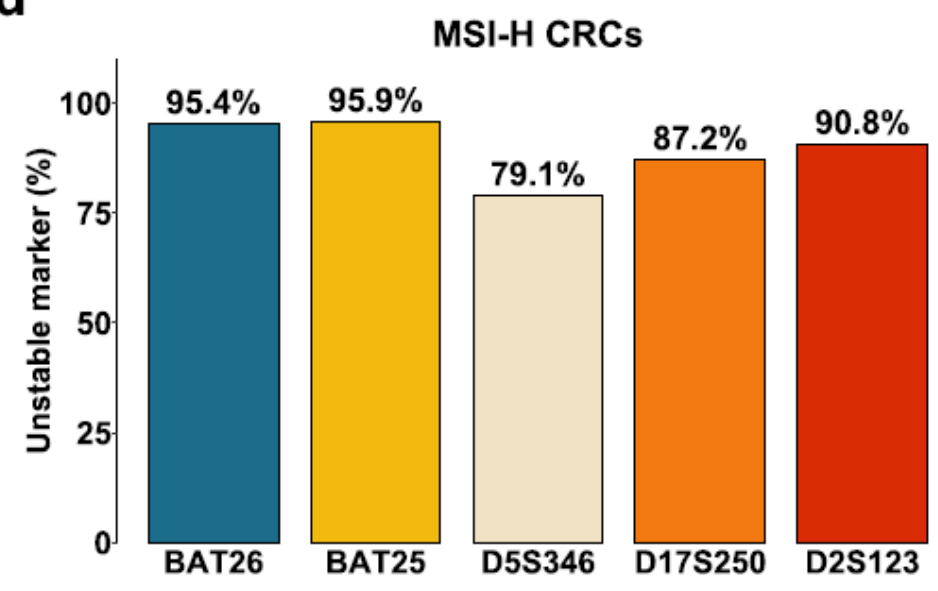

Figure 5

The sensitivity of the five NCl panels for MSI-L ( $A$ and $C$ ) and MSI-H (B and D) cases in GCs ( $A$ and $B$ ) and CRCs (C and D). 


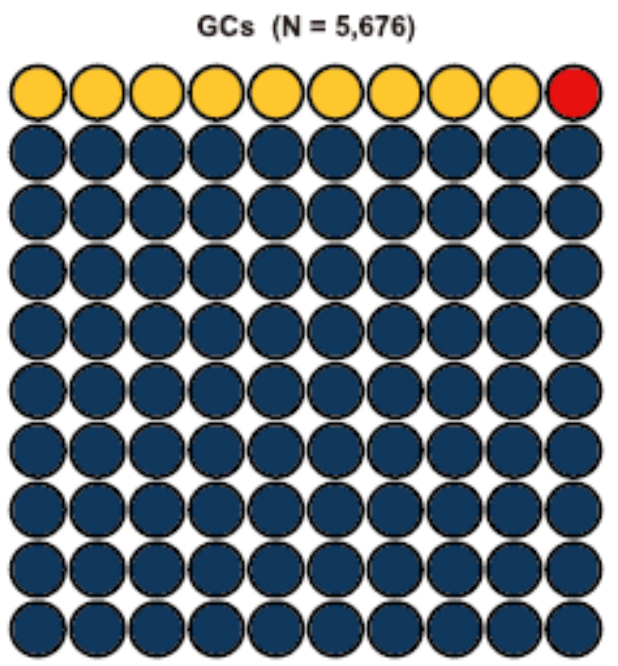

口 MSI-H and dMMR ( $\mathrm{N}=521,9.2 \%)$

Discordant or indeterminate $\mathrm{IHC}$ case $(\mathrm{N}=54,0.9 \%)$

C

$$
\text { 口 MSS/MSI-L and PMMR ( } N=5,101,89.9 \%)
$$

GCs except MSS/MSI-L and pMMR (N = 575)

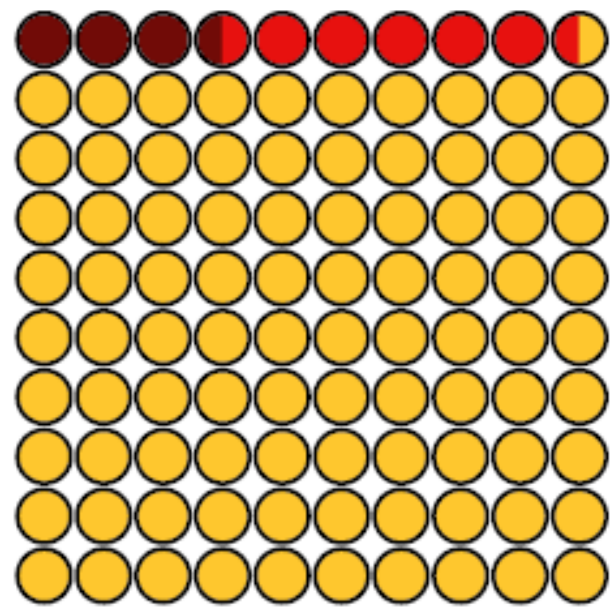

Discordant case ( $\mathrm{N}=19,3.3 \%)$

Indeterminate IHC ( $\mathrm{N}=35,6.1 \%)$

MSI-H and dMMR ( $\mathrm{N}=521,90.6 \%)$

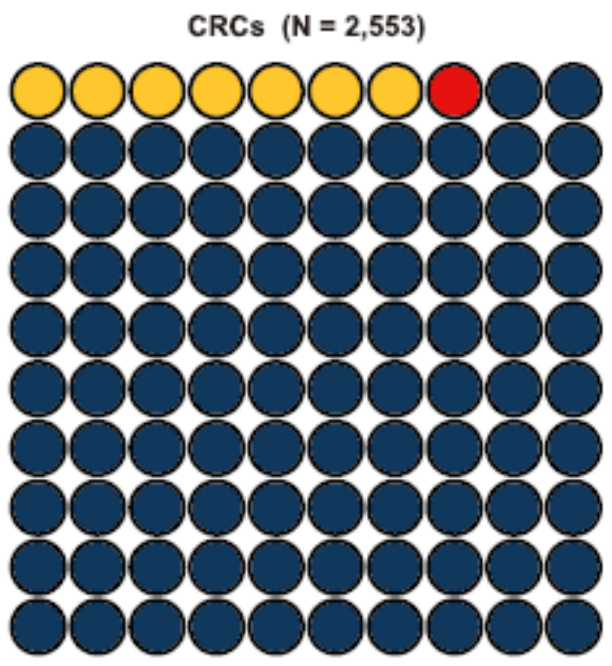

Q MSI-H and dMMR $(\mathrm{N}=176,6.9 \%)$

Discordant or indeterminate IHC case $(\mathrm{N}=29,1.1 \%)$

MSS/MSI-L and PMMR $(\mathrm{N}=2,348,92.0 \%)$

CRCs except MSS/MSI-L and pMMR $(\mathrm{N}=205)$

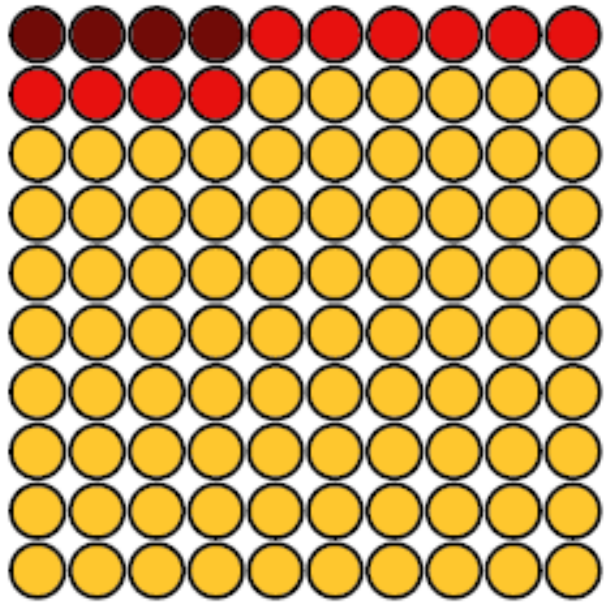

Discordant case $(\mathrm{N}=8,3.9 \%)$

Indeterminate IHC $(\mathrm{N}=21,10.2 \%)$

Q MSI-H and dMMR $(\mathrm{N}=176,85.9 \%)$

Figure 6

Comparison between PCR-based MSI and MMR protein IHC in GCs and CRCs. MSI-H and dMMR cases, Discordant or indeterminate IHC cases, or MSS/MSI-L and pMMR cases in all GCs (A) and CRCs (B). Despite re-evaluation, discordant or indeterminate IHC cases were observed in GCs (C) and CRCs (D), excluding unequivocal MSS/MSI-L and pMMR cases. 

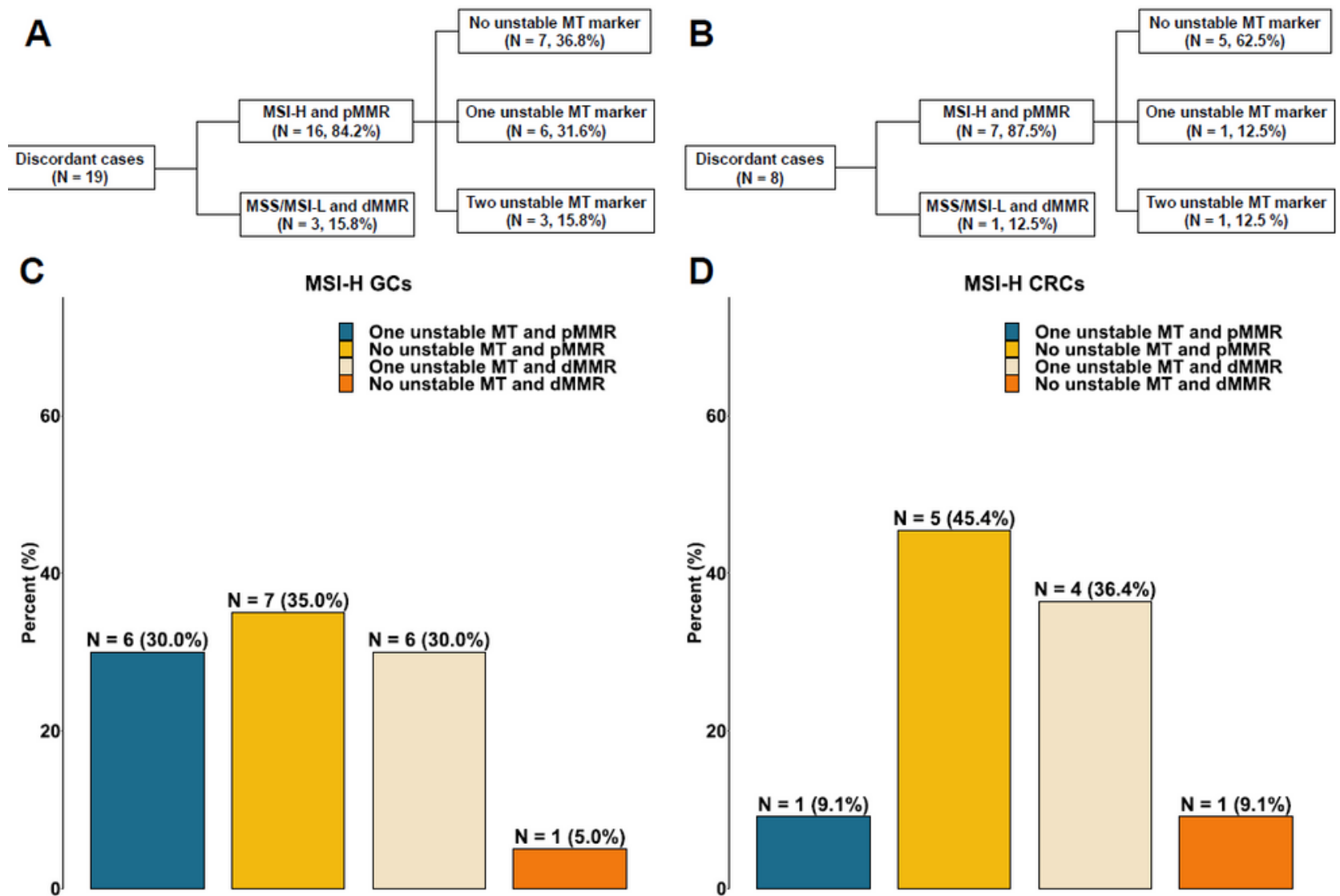

D

MSI-H CRCs

One unstable MT and pMMR

No unstable MT and PMMR

One unstable MT and dMMR

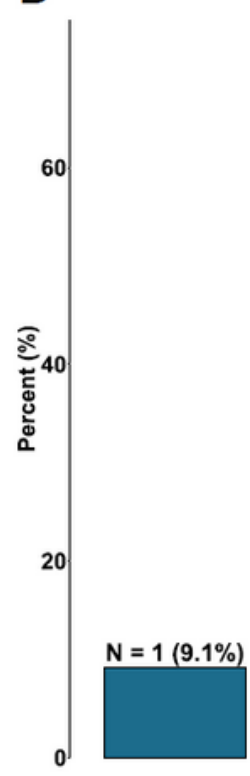

One unstable MT and pMMR

No unstable MT and PMMR

One unstable MT and dMMR

No unstable MT and dMMR

\section{E}
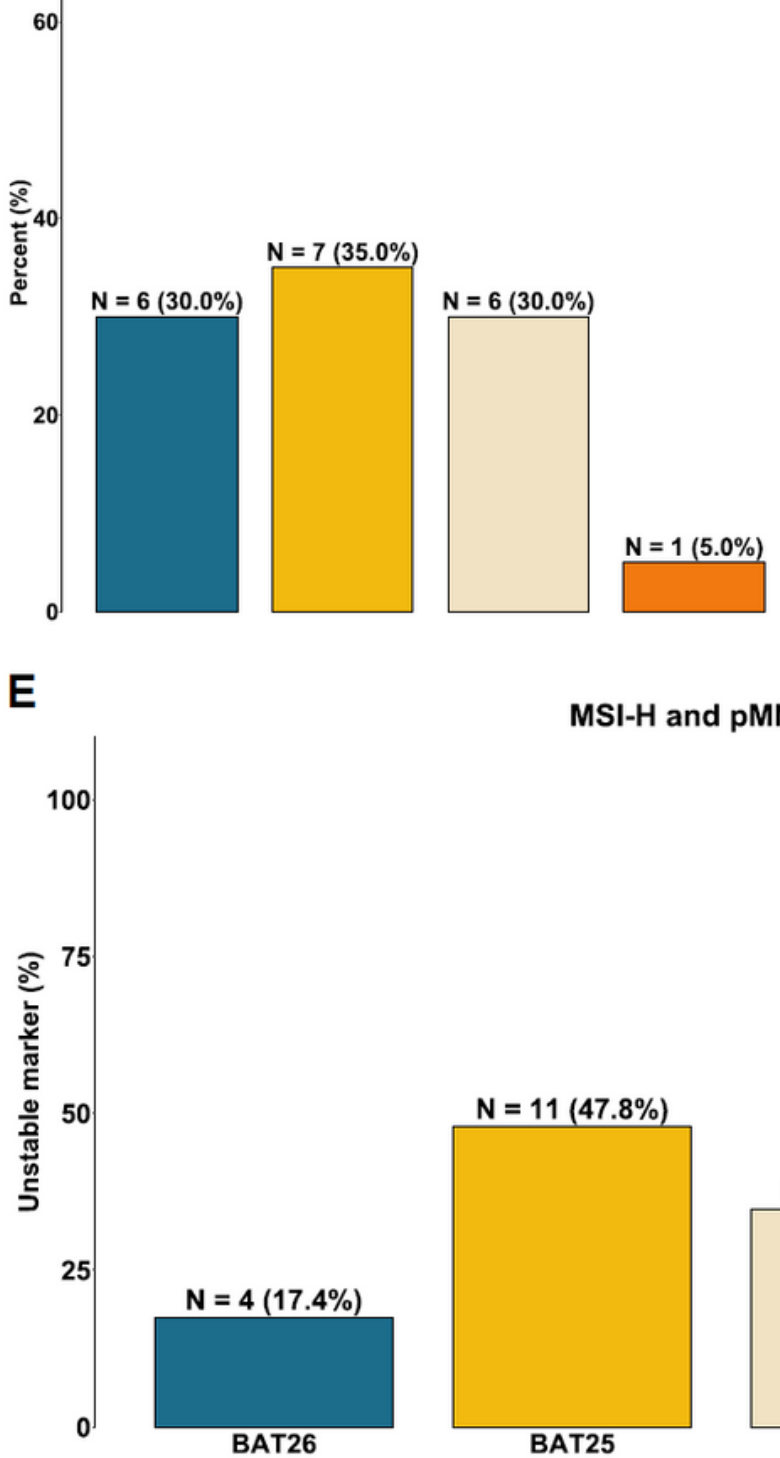

$\mathrm{N}=1(5.0 \%)$

MSI-H and pMMR GCs and CRCs (N = 23)
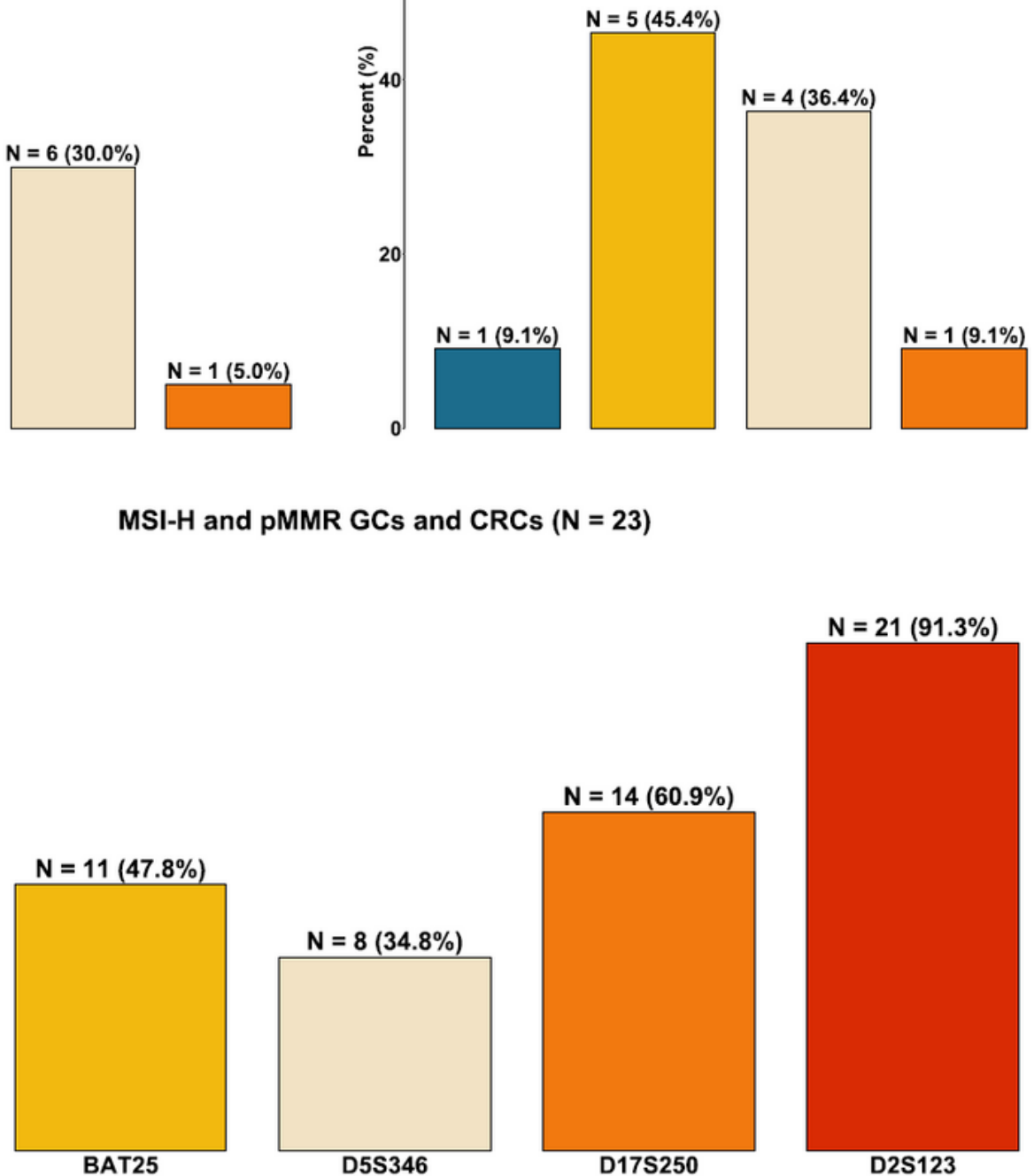

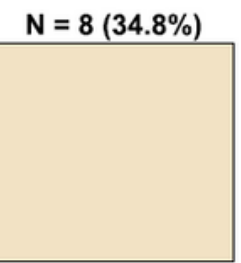

D5S346

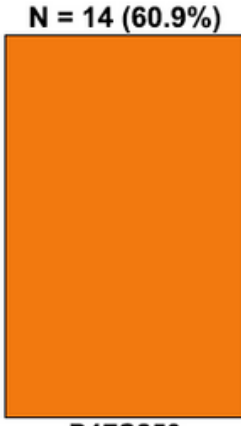

D17S250

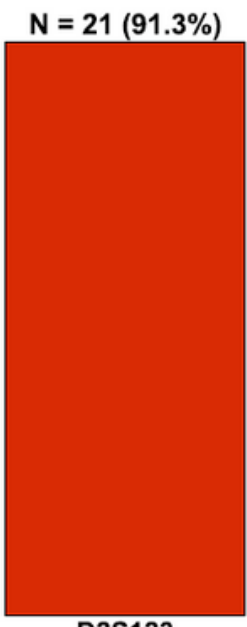

D2S123

\section{Figure 7}

Discordant cases and comparison of five markers for MSI testing and MMR IHC in MSI-H GCs and CRCs. Among discordant cases in GCs (A) and CRCs (B), MSI-H and pMMR cases were classified as the number of unstable MT markers. The distribution of dMMR and pMMR, except for indeterminate IHC in MSI-H GCs (C) and CRCs (D), with or without only one unstable MT. The proportion of unstable markers among the five markers in MSI-H and pMMR GCs and CRCs (E). 


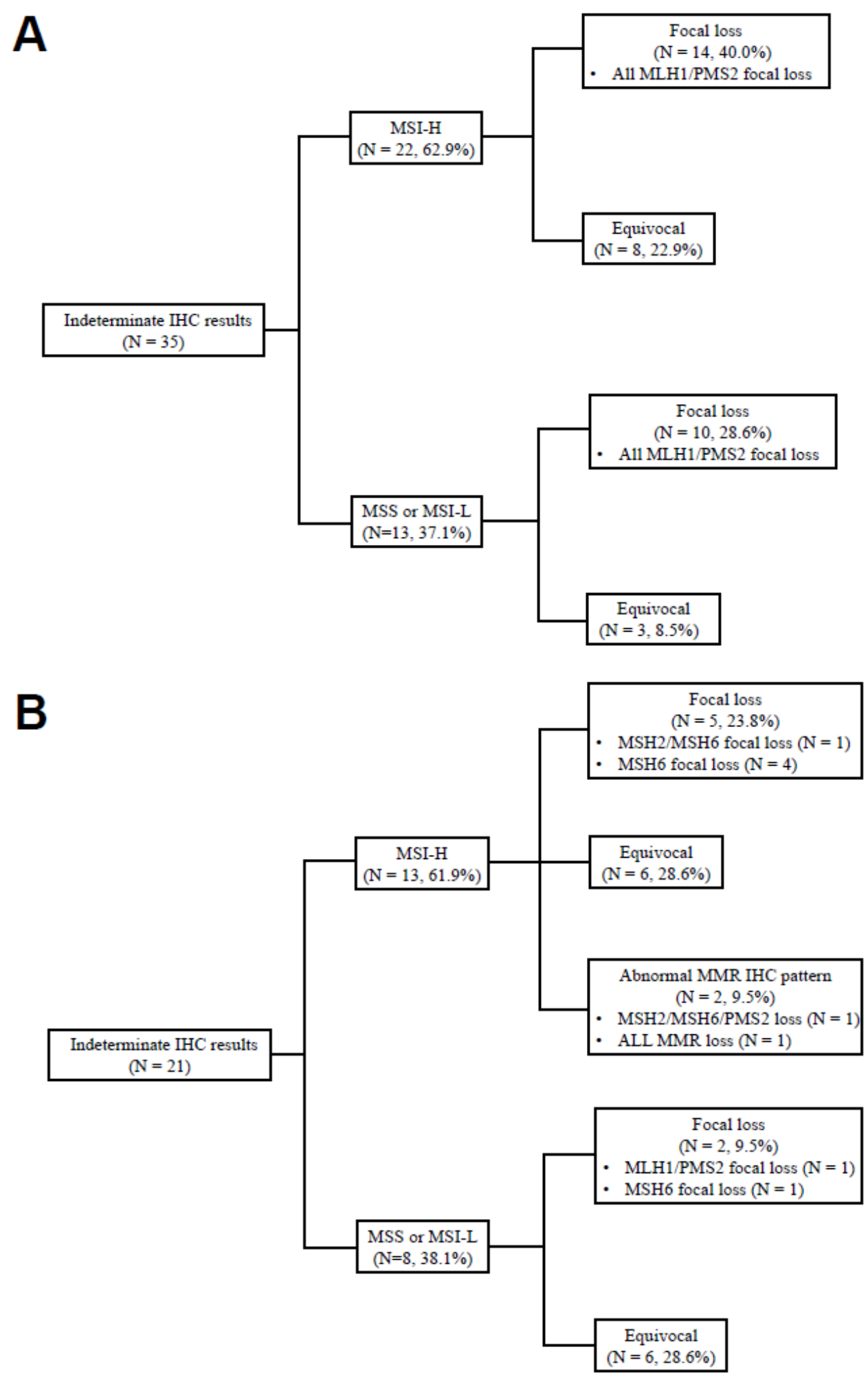

Figure 8

Indeterminate IHC results of GCs (A) and CRCs (B). 